\title{
Revisão de literatura: cunicultura e o uso de aditivos na alimentação
}

\author{
Literature review: culture and the use of food additives \\ Revisión de la literatura: cría de conejos y uso de aditivos alimentarios
}

Recebido: 23/09/2021 | Revisado: 30/09/2021 | Aceito: 04/10/2021 | Publicado: 10/10/2021

Paola Cristina de Piza
ORCID: https://orcid.org/0000-0002-0759-9760
Universidade José do Rosário Vellano, Brasil
E-mail: paolacristinapiza@gmail.com
Andressa Santanna Natel
ORCID: https://orcid.org/0000-0002-8252-1090
Universidade José do Rosário Vellano, Brasil
E-mail: andressa.natal@ unifenas.br
Lucas Alberto Teixeira de Rezende
ORCID: https://orcid.org/0000-0003-3570-3892
E-mail: lucas.teixeira@ @muz.ifsuldeminas.edu.br
Edina de Fátima Aguiar
ORCID: https://orcid.org/0000-0002-7883-5628
Universidade José do Rosário Vellano, Brasil
E-mail: edina.aguiar@unifenas.br
Guilherme Carvalho Rocha
Instituto Federal de Educação, Ciência e Tecnologia do Sul de Minas Geral, Brasil
ORCID: https://orcid.org/0000-0001-6435-5423
Universidade José do Rosário Vellano, Brasil
E-mail: rochaguicarvalho@gmail.com
Estêvão Luís de Araújo Oliveira Morais
ORCID: https://orcid.org/0000-0002-1090-0892
E-mail: estevao.morais@hotmail.com

\section{Resumo}

A cunicultura é o ramo da zootecnia que trata da criação produtiva, econômica e racional de coelhos. A partir da Segunda Guerra Mundial, houve-se a necessidade de se produzir, de forma mais rápida e eficiente, produtos de origem animal para o consumo humano. Sendo assim, os coelhos despertaram interesse por serem animais prolíferos, dóceis e de ciclo reprodutivo rápido. A criação de coelhos pode ser considerada uma atividade de fácil implantação, com manejo e instalações simples; produzindo uma carne de ótima qualidade para a alimentação humana e seus subprodutos que podem ser comercializados em grande escala, podendo ser uma ótima opção de fonte de renda para pequenos e grandes produtores. A alimentação é o ponto crucial para alcançar bons índices produtivos; assim como os demais sistemas de produção, na cunicultura a alimentação representa de 60 a $70 \%$ dos custos. Devido a isto, o uso de aditivos procura aumentar a eficiência alimentar, proporcionando melhores desempenhos produtivos e econômicos na produção animal. Os nucleotídeos são compostos por uma base nitrogenada (purina ou pirimidina), uma pentose e um ou mais grupos fosfatos. Dentro da nutrição animal, os nucleotídeos dietéticos têm chamado atenção por desempenhar papel na manutenção da saúde intestinal, podendo atuar como uma solução ao uso de antibióticos na alimentação dos animais jovens. Portanto, destaca-se a importância de estudos e pesquisas para se obter novas alternativas na alimentação para os sistemas de produção e manter os dados sobre cunicultura ativos.

Palavras-chave: Aditivos; Alimentação; Coelhos; Nucleotídeos; Sistema de produção.

\begin{abstract}
Cuniculture is the branch of animal husbandry that deals with the productive, economic and rational breeding of rabbits. From the Second World War onwards, there was a need to produce, more quickly and efficiently, products of animal origin for human consumption. Thus, rabbits aroused interest because they are prolific, docile and fast reproductive animals. Raising rabbits can be considered an easy-to-implement activity, with simple management and installations, producing excellent quality meat for human consumption and its by-products that can be commercialized on a large scale and can be a great source of income for small and large producers. Food is the crucial point to achieve good production rates; as with other production systems, in rabbit farming, feeding represents 60 to $70 \%$ of the costs. Due to this, the use of additives seeks to increase feed efficiency, providing better productive and economic performance in animal production. Thus, nucleotides are additives composed of a nitrogenous base (purine or pyrimidine), a pentose and one or more phosphate groups. Within animal nutrition, dietary nucleotides have drawn attention for playing a role in the maintenance of intestinal health and may act as a solution to the use of antibiotics in the feeding of young
\end{abstract}


animals. Therefore, it highlights the importance of studies and research to obtain new alternatives in feeding for production systems and keep data on rabbit production active.

Keywords: Additives; Food; Rabbits; Nucleotides; Production system.

\section{Resumen}

La cunicultura es la rama de la ganadería que se ocupa de la cría productiva, económica y racional de conejos. Desde la Segunda Guerra Mundial en adelante, fue necesario producir, de manera más rápida y eficiente, productos de origen animal para el consumo humano. Así, los conejos despertaron interés por ser animales prolíficos, dóciles y de rápida reproducción. La cría de conejos se puede considerar una actividad fácil de implementar, con un manejo e instalaciones simples, produciendo carne de excelente calidad para el consumo humano y sus subproductos que pueden ser comercializados a gran escala y pueden ser una gran fuente de ingresos para pequeños y pequeños. grandes productores. La alimentación es el punto crucial para lograr buenos índices de producción; Al igual que con otros sistemas de producción, en la cría de conejos, la alimentación representa del 60 al $70 \%$ de los costos. Debido a esto, el uso de aditivos busca incrementar la eficiencia alimenticia, brindando un mejor desempeño productivo y económico en la producción animal. Así, los nucleótidos son aditivos compuestos por una base nitrogenada (purina o pirimidina), una pentosa y uno o más grupos fosfato. Dentro de la nutrición animal, los nucleótidos de la dieta han llamado la atención por desempeñar un papel en el mantenimiento de la salud intestinal y pueden actuar como una solución al uso de antibióticos en la alimentación de animales jóvenes. Por tanto, destaca la importancia de los estudios e investigaciones para obtener nuevas alternativas en la alimentación para los sistemas de producción y mantener activos los datos sobre la producción de conejos.

Palabras clave: Aditivos; Alimentos; Conejos; Nucleótidos; Sistema de producción.

\section{Introdução}

A cunicultura constitui-se em uma ciência de fácil aplicação, sobretudo em pequenas propriedades rurais, devido ser de fácil implementação e de baixo custo, além de ser uma fonte de renda não só pela produção de carne, mas também pelo aproveitamento de subprodutos, com: esterco, pele, pelo, sangue e vísceras (Mello \& Silva, 2012). A pesquisa na área da cunicultura tem, além de apelo científico, a pretensão social, uma vez que, por apresentar manejo, alojamento e alimentação simples, pode possibilitar uma nova fonte de renda ao pequeno produtor, se enquadrando no perfil de agricultura familiar

Assim como em outros sistemas de produção na cunicultura, a alimentação é o ponto crucial para alcançar bons índices produtivos dos plantéis. As rações devem ser equilibradas para cada fase de desenvolvimento, fornecendo nutrientes necessários, para se obter um bom estado sanitário, atingindo o peso comercial em curto tempo, alcançar desenvolvimento reprodutivo mais cedo, o que é o desejável (Ferreira, et al., 2015), além de melhorar a rentabilidade do sistema. Para atingir tais objetivos, o uso de alimentos alternativos, bem como aditivos e substâncias naturais na dieta desses animais tem se tornado cada vez mais frequente, visando melhorar a eficiência alimentar e redução dos custos, com o menor uso de coccidiostáticos (Ferreira, et al., 2015).

O uso de aditivos em rações visa aumentar a eficiência alimentar, proporcionando melhores desempenhos produtivos e econômicos na produção animal. Os nucleotídeos são aditivos compostos por uma base nitrogenada (purina ou pirimidina), uma pentose e um ou mais grupos fosfatos (Lehninger, et al., 1995). São componentes intracelulares de baixo peso molecular, integrados a numerosos processos metabólicos e essenciais para todas as células (Mateo, et al., 2004).

Ainda que, a suplementação com nucleotídeos para animais não é essencial, quando fornecido pode se obter resultados sobre a divisão celular, crescimento de células, modulação do sistema imunológico e manutenção da saúde intestinal, reduzindo a incidência de doenças entéricas (Rossi, et al., 2007) e, consequentemente, com melhorar no desempenho animal. Esses resultados estão relacionados a ação benéfica dos antibióticos, desta forma, o uso de nucleotídeos, atendendo a demanda por redução ao uso de antibióticos na alimentação animal, visando a segurança alimentar.

Dentro da nutrição animal, os nucleotídeos dietéticos têm chamado atenção por desempenhar papel na manutenção da saúde intestinal, podendo atuar como uma solução ao uso de antibióticos na alimentação dos animais jovens. Além disso, a inclusão de nucleotídeos dietéticos na nutrição humana possibilitou desenvolvimento do sistema imune (Rossi, et al., 2007). 
Os nucleotídeos modificam o tipo e o crescimento da microflora intestinal (Uauy, et al., 1994), favorecendo o desenvolvimento da flora fecal com predominância de bifidobacterias, semelhante à observada no leite materno. Essas bactérias têm efeito benéfico, reduzindo o $\mathrm{pH}$, que por sua vez suprime a proliferação de bactérias patogênicas. As bifidobactérias também inibem o crescimento de enterobactérias responsáveis por doenças que causam diarreia (Rossi et al., 2007).

Desta forma, busca-se estudar a ação dos nucleotídeos em substituir os quimioterápicos em sua ação benéfica na alimentação animal, sem causar perdas de produtividade, levando em consideração os custos de produção, a resistência de microrganismos e resíduos no produto final, diferente dos antibióticos.

\section{Metodologia}

O presente trabalho se caracteriza como pesquisa bibliográfica que, segundo Gil (2021), vale-se de materiais desenvolvidos com a finalidade de reavivar trabalhos já elaborados sobre uma determinada temática. Para a realização desta revisão bibliográfica, foram pesquisados dados de artigos, livros, sites, associações e órgãos governamentais dentro de um período de datas de 1987 a 2021. Estes dados são referentes a cunicultura e aos nucleotídeos, e como são utilizados na alimentação animal.

A cunicultura sempre apresentou grande importância em pesquisas laboratoriais, e se demonstrou ser uma ótima fonte de proteína de origem animal para a alimentação humana ao longo da história. Nos tempos atuais, a criação de coelhos também cresceu nos mercados de animais de companhia, o marcado pet. Porém, mesmo sendo um sistema de produção versátil, os produtores e consumidores enfrentam dificuldades em se obter dados cientificamente comprovados. Existem muitas linhas de pesquisas que utilizam coelhos, buscando o melhoramento genético, o bem-estar animal, o melhor desempenho, alimentos com melhor qualidade para as dietas, entre outros vários estudos, que procuram o reconhecimento da importância destas pesquisas. Desta forma, observa-se a importância da divulgação dos sistemas de criação, produção e comercialização de coelhos Brasil, dos estudos realizados, podendo se tornar uma alternativa de renda para a agricultura familiar.

\section{Revisão de Literatura}

\subsection{Panorama da cunicultura}

De acordo com os dados da FAO (2019), o continente Asiático possui uma produção de 443.146/1000 cabeças, produzindo 626.544 toneladas de carne de coelho para o mercado interno e externo. Em segundo lugar o continente Europeu (113.151/1000 cabeças; 170.751 toneladas, em terceiro lugar a África com uma produção de 63.479/1000 cabeças, e 71,122 toneladas de carne para o comercio, e as Américas representam uma produção de 13.237/1000 cabeças, gerando uma produção de carne de 15.519 toneladas. O Brasil, conforme dados da FAO (2017) ocupa a trigésima oitava posição (38 $)$ com uma população estimada em cento e setenta e nove mil coelhos (179.000).

No Brasil, poucos são os estabelecimentos que trabalham exclusivamente com coelhos, a grande maioria dos produtores tem a cunicultura como atividade secundária (Machado, 2012). A atividade de criação desses animais tem um custo relativamente baixo, pois utiliza pouco espaço e instalações rústicas. Sendo vista como uma fonte de renda alternativa para a agricultura familiar, bem como produção para consumo próprio e comercialização.

De acordo com dados do IBGE (2017) a população nacional de coelho é de 200.345 cabeças, com uma produção anual de 1.319 toneladas de carne (FAO, 2017). Se considerarmos o consumo per capita de 0,100 kg/ano (SEBRAE, 2016) e, uma população nacional estimada em 211.258.981 habitantes, temos um déficit de produção para atender o mercado interno de 19,8 toneladas/ano, o que representa espaço para crescimento do produtor. 
No Brasil, os dados concretos sobre a produção de coelhos são pouco atualizados. O senso agropecuário de 2006 apontava uma população total de 295.584 animais, distribuídos em 17.615 estabelecimentos, sendo uma média de 17 animais por estabelecimento. Lembrando que a grande parte dessa produção é levada como uma segunda opção de fonte de renda, principalmente para a agricultura familiar (IBGE, 2012). O senso revela que a cunicultura é praticada em estabelecimentos pequenos, sendo $45 \%$ dos estabelecimentos com área de até 10 ha. Porém, nos últimos anos o interesse pela cunicultura tem aumentado, principalmente por seu potencial de produção de carne de alto valor nutricional, pela pele de excelente qualidade e além dos seus subprodutos, com aplicações que vão desde a produção de peças artesanais a artigos das indústrias têxteis e produtos para a indústria farmacêutica.

O Brasil, segundo os mesmos dados, produz cerca de mil trezentos e dezenove toneladas (1.319) de carne de coelho, o que corresponde à trigésima oitava colocação (38). De acordo com dados do IBGE (2012), o consumo da carne de coelho no Brasil ainda é considerado pequeno, já que o consumo médio está em torno de $0,12 \mathrm{~kg} / \mathrm{hab} / \mathrm{ano}$, enquanto que outras carnes, como a bovina, chegam a 37,4 kg/hab/ano e a de frango, a 43,9 kg/hab/ano. Porém, a FAO desde 1999, destaca a necessidade de treinamento em técnicas de criação de coelhos, devido à sua limitação para a difusão resultante a de antigos preconceitos contra a carne de coelho. Segundo Forrester-Anderson, et al., (2006), em estudos realizados em 64 países em desenvolvimento revelou que $30 \%$ das pessoas entrevistadas consideravam que razões sociais, religiosas ou outras desencorajariam a criação de coelhos. Levando em consideração que é mais fácil incentivar o consumo de carne de coelho onde a população já está acostumada a comer diferentes tipos de carne. A partir deste ponto, levando em consideração a busca por alimentos mais saudáveis, uma alternativa para a população, seria a carne de coelho que apresenta uma menor quantidade de colesterol, de gordura e sódio, comparado às carnes de aves, de suíno e cordeiro.

O efetivo de coelhos Brasileiro apresentou uma queda, em comparação às demais produções, de 12,4\% entre $2011 \mathrm{e}$ 2012, tendo o registro de 204,831 mil animais no ano-base. O maior efetivo de coelhos encontra-se na região Sul do país, sendo os três Estados componentes desta região os mantenedores dos rebanhos mais importantes, totalizando $75,7 \%$ da produção brasileira: Rio Grande do Sul, 40,9\%; Santa Catarina, 18,3\%; e Paraná, 16,5\%. Em termos municipais, aparecem os municípios de Dois Irmãos (RS), Mogi das Cruzes (SP) e Santa Maria (RS) como os principais produtores de coelhos (IBGE, 2012).

A cadeia da cunicultura deve ser desenvolvida, pois ainda é uma cultura pouco explorada no Brasil, com um elevado potencial de mercado a ser atendido. Por outro lado, deve-se lembrar que a produção animal enfrenta atualmente desafios globais, como a necessidade de melhoria na sustentabilidade dos sistemas de produção, visando a intensificação da produção sem esquecer a segurança alimentar (Roos, et al., 2017).

\subsection{Cunicultura}

Os coelhos hoje explorados são descendes do coelho europeu, cientificamente denominado Oryctolagus cuniculus, que sofreu uma domesticação tardia, comparado a outros animais de produção. Em virtude da Segunda Guerra Mundial, houve-se a necessidade de se produzir, de forma mais rápida e eficiente, produtos de origem animal. Sendo o fato de o coelho é um animal prolífero, dócil e de ciclo rápido, despertou-se o interesse em melhorar o desempenho destes animais, para animais de corte (Klinger \& Toledo, 2018). Isto devido ao rápido crescimento, sua precocidade reprodutiva, sua prolificidade, seu pequeno período de gestação e a pouca necessidade de espaço físico pequeno.

A cunicultura pode ser considerada uma atividade de fácil implantação com manejo e instalações simples (Simonato, 2008). Outra vantagem da cunicultura é que o animal pode ser aproveitado e comercializado quase em sua totalidade. Além da carne, pele e pelos, é possível a comercialização de outras partes como: cérebro, orelhas, carcaça, esterco e sangue. Apesar de proporcionar um retorno rápido ao produtor, no Brasil a cunicultura ainda é pouco desenvolvida. Entretanto é um mercado com 
bom potencial principalmente quando se considera que a cunicultura é uma atividade estratégica, pois é uma atividade sustentável, produz alimentos de alta qualidade nutricional, tem elevada produtividade, aproveitamento de quase todos os subprodutos, baixa necessidade de água e baixo impacto ambiental (Machado, 2012).

Dentro da cadeia de produção de carne, o coelho pertence ao grupo de alimentos como menor custo e de boa qualidade nutricional, pois proporciona uma opção de proteína saudável e nutritiva. A criação de coelhos pode ser implementada como uma atividade familiar produtiva, trazendo benefícios importantes, como melhor nutrição para famílias com recursos econômicos limitados, geração de emprego familiar e diversificação de renda através da obtenção de subprodutos como a pele e pelo, que podem ser usados em artesanato para a preparação de várias peças de vestuário; bem como usar esterco de coelho como fertilizante orgânico e melhorar sua produtividade (Romain, 2015).

\subsection{Produção e índices zootécnicos}

A produção de coelhos que se iniciou na década de oitenta, pois os sistemas de produção tiveram interesse para a fabricação de lã (neste perfil se encaixava a raça angorá). No final da década de oitenta, os cunicultores observaram uma oportunidade na produção de carne, porém o setor não conseguiu se manter devia a falta de adaptação a novas tecnologias e principalmente pela falta de estrutura do setor (Machado, 2012). Mesmo assim, a cunicultura apresentou nos últimos anos sinais de crescimento, quando se comparado ao final dos anos 80, principalmente o mercado pet (Ferreira, 2006; Machado, 2012; Machado, et al. 2021).

Para o mercado de corte, além de vários subprodutos da cunicultura, a carne de coelho se destaca no mercado possui uma relação ácidos graxos saturados/insaturados menores, quando comparada com a carne bovina. Além de apresentar uma menor quantidade de colesterol $(50 \mathrm{mg} / 100 \mathrm{~g}$ produto) em comparação à carne bovina $(140 \mathrm{mg} / 100 \mathrm{~g})$, de acordo com a Associação Científica Brasileira de Cunicultura - ACBC (2010).

A carne de coelho é uma carne branca, saborosa e macia. Estas características torna a carne de coelho notoriamente apreciada por suas propriedades nutricionais e dietéticas, sendo uma carne magra e os lipídeos altamente insaturados (60\% do total de ácidos graxos), baixo teor de colesterol $(50 \mathrm{mg} / 100 \mathrm{~g}$ ), alto teor de proteína (cerca de 25,5\%), sendo ainda pobre em sódio, porém, rica em potássio, fósforo e magnésio (Klinger \& Toledo, 2012).

Os coelhos que estão prontos para o abate apresentam um peso comercial de mais ou menos 1,8 a 2,3 kg de peso vivo e precisam estar em condições plenas de saúde. O peso de cada carcaça varia entre 1,0 e 1,6 kg, correspondendo a $60 \%$ de rendimento de carcaça. A gordura e ossos apresentam apenas 14\% do peso total da carcaça (Mello \& Silva, 2012).

Segundo o senso de 2012 (IBGE), pode se observar que houve uma queda no rebanho brasileiro de coelhos nos anos de 2001 a 2012, onde a produção inicial era de 348,8 mil cabeças e caiu para 204,8 mil cabeças. Porém, o estado de Minas Gerais, aumento a sua participação no rebanho nacional com 7,2 \%, ocupando a quarta posição no ranking do efetivo rebanho de coelho por estado, sendo a região do Sul de Minas Gerais, representando 21\% da produção do estado.

Segundo Machado et al. (2021), os dados sobre a cunicultura são escassos e faltam dados consistentes. Os dados publicados revelam que a cunicultura é praticamente desenvolvida em pequenas propriedades, sendo uma alternativa de renda. Os dados sobre a produção de coelhos são questionáveis, o que reforça que sempre são necessárias pesquisas que revelem, com precisão, a real população desses animais.

Devido a isto, estima-se que o número de cunicultores de corte no Brasil, seja de aproximadamente 1.050 animais, sendo deste número 99.750 animais alojados em granjas, gerando uma receita mensal para o país de aproximadamente $\mathrm{R} \$$ 1.911.000,00. Sendo, estes valores considerando que metade dos animais são abatidos com inspeção em frigoríficos. Já o mercado pet, com seu crescente no último ano, possui uma estimativa de 1.300 animais, com 49.440 animais alojados em 
granjas, totalizando uma receita mensal de $\mathrm{R} \$ 6.500 .000,00$. Tendo em conta, que estes valores podem ter alguns itens a mais vendidos pelos produtores (Machado, et al., 2021).

Segundo Militão (2011), para a comercialização do produto, os produtores de coelhos investem na construção de galpões, na compra de equipamentos, em medicamentos e nos animais. Mesmo assim a produção de coelhos no Brasil é considerada lenta.

O consumo de carne de coelho é considerado baixa, devido a sua produção e comercialização; mas também a sua produção e comercialização são baixos, devido ao baixo consumo de carne, estando interligados entre si. Lembrando sempre que na cadeia produtiva na cunicultura, o produtor é o que recebe a menor remuneração, principalmente quando se compara os investimentos realizados para se iniciar a produção (Duarte, 2011).

\subsection{Metabolismo alimentar de coelhos}

Os coelhos são animais herbívoros, monogástricos, que não se adaptaram com dietas fareladas. A alimentação destes animais é fornecida em forma peletizada, onde é possível associar forragens frescas ou fenadas (Ferreira et al., 2002). O hábito alimentar dos coelhos caracteriza pela ingestão de pequenas quantidades de alimento por vez e com grande frequência, apresentando a capacidade de ajustar a quantidade de alimento consumido (Klinger \& Toledo, 2018).

Ao longo do processo evolutivo, os animais herbívoros desenvolveram a capacidade de aproveitar alimentos ricos em parede celular, através de processos simbióticos com microrganismos e especificidades da anatomia e fisiologia de cada espécie. Os coelhos, assim como os ruminantes e equinos, possui câmaras de fermentação, porém, nos coelhos elas ficam localizadas após o intestino delgado, especificamente no ceco, sendo os sítios de maior absorção de nutrientes, onde devido a isto limita o aproveitamento do material fermentado, sendo absorvido somente de 16 a $18 \%$ da digestibilidade da parede celular vegetal (Ferreira, et al., 2006).

Sendo assim, os coelhos apresentam uma dualidade na excreção fecal, sendo capazes de produzir e reingerir parte do material fecal, denominadas de fezes moles ou cecotrofos, que são produzidos através da fermentação cecal, denominada de cecotrofia. O que permite aproveitar com mais eficiência os nutrientes dos alimentos vegetais (Ferreira et al., 2002).

O alimento já ingerido, inicia a sua digestão no estômago e caminha para o intestino delgado que tem a sua digestão completa. Devido aos movimentos peristálticos intestinais, a digesta vai para o intestino grosso onde a válvula íleo-cecal impede o retorno. Neste momento acontece a etapa característica e complexa no processo digestivo dos coelhos, onde consiste na formação de dois produtos distinto, as fezes e os cecotrofos (Mello \& Silva, 2012). Os cecotrofos são produzidos no ceco, revestidos com uma membrana de muco, que os torna um conjunto com característica pastosa, moldados no cólon proximal; enquanto as fezes apresentam características firmes e distintas entre si (Klinger \& Toledo, 2018).

Segundo Klinger e Toledo (2018), a absorção dos nutrientes é realizada em duas etapas, a primeira são os resíduos que após a absorção, passam sem serem absorvidos e são eliminados através das fezes. E a segunda etapa, é a absorção dos nutrientes desdobrados no ceco e que não tiveram tempo de sofrer absorção. As partículas menores e mais digestivas da digesta, vão para o ceco, onde ocorre a digestão microbiana entre 10 a 12 horas, ocorrendo a formação dos cecotrofos que apresentam nível elevados de proteína, vitaminas C, K, e do complexo B (Mello \& Silva, 2012). Podendo se observar na tabela 1, a composição das fezes duras e a dos cecotrofos. 
Tabela 1. Composição de fezes duras e moles (valores médios e faixa de variação).

\begin{tabular}{lcc}
\hline \multicolumn{1}{c}{ COMPONENTES } & FEZES DURAS & CECOTROFOS \\
\hline Matéria seca $(\mathrm{g} / \mathrm{Kg})$ & $603(464-671)$ & $349(276-427)$ \\
Proteína Bruta $(\mathrm{g} / \mathrm{kg}$ de MS) & $126(54-189)$ & $289(218-427)$ \\
Fibra Bruta $(\mathrm{g} / \mathrm{kg}$ de MS) & $322(194-428)$ & $184(131-276)$ \\
Cinzas $(\mathrm{g} / \mathrm{kg})$ de MS) & $90(77-167)$ & $125(95-168)$ \\
$\mathrm{Na}+(\mathrm{mmol} / \mathrm{kg} \mathrm{MS})$ & 45 & 120 \\
$\mathrm{~K}+(\mathrm{mmol} / \mathrm{kg} \mathrm{MS})$ & 95 & 280 \\
$\mathrm{PO}^{2}-4(\mathrm{~g} / \mathrm{Kg} \mathrm{MS})$ & 10 & 110 \\
Ácido nicotínico $(\mu \mathrm{g} / \mathrm{g})$ & 39,70 & 139,10 \\
Riboflavina $(\mu \mathrm{g} / \mathrm{g})$ & 9,40 & 30,20 \\
Ácido pantotênico $(\mu \mathrm{g} / \mathrm{g})$ & 8,40 & 51,60 \\
Vitaminas B12 $(\mu \mathrm{g} / \mathrm{g})$ & 0,90 & 2,90 \\
\hline
\end{tabular}

Fonte: Adaptado de Santomá et al. (1989).

Os cecotrofos são secretados somente à noite, e são ingeridos diretamente do ânus, com a ajuda da sucção que o animal realiza. Uma vez captados, os cecotrofos ingeridos vão para o estômago, e permanecem de 6 a 8 horas para completar a digestão microbiana (Klinger \& Toledo, 2018).

\subsection{Trato gastrointestinal em coelhos}

Para a absorção dos nutrientes e desempenho dos animais, tudo se inicia no processo de digestão, através do trato gastrointestinal. Este como os demais animais é constituído por boca, língua, esôfago, intestino delgado, intestino grosso e ânus. Onde possuem a função de digerir os alimentos, possibilitando a absorção dos nutrientes (Klinger \& Toledo, 2018; Mello \& Silva, 2012).

De acordo com Mello e Silva (2012), a digestão se inicia na boca; os coelhos apresentam 28 dentes, 6 incisivos, 10 pré-molares e 12 molares, que tem como função de apreender os alimentos e tritura-los, para diminuir o tamanho das partículas. Com a ajuda da língua, as partículas são misturadas com a saliva, contribuindo para o processo de mastigação e deglutição. A língua apresenta papilas gustativas, ajuda no processo de absorção de água e dos cecotrofos por sucção.

Através do esôfago o alimento se desloca para o estômago com a ajuda dos movimentos peristálticos. O estômago é dividido em três regiões: região fundida, região cárdica e região pilórica. A região fundida, exerce a função de depósito dos alimentos, sendo o local onde ocorre a complementação da digestão microbiana dos cecotrofos. A região cárdica, é provida de glândulas secretoras do suco gástrico, sendo o local onde ocorre a digestão química dos alimentos; e a região pilórica promove contrações musculares, que encaminham a digesta para o intestino delgado (Mello \& Silva, 2012).

O intestino delgado é dividido em três porções: duodeno, jejuno e íleo. É uma região que possui muitas glândulas secretoras de substâncias digestivas e imunológicas. No duodeno, a digesta ácida proveniente do estômago é misturada com secreções neutralizantes e digestivas do próprio duodeno, do fígado e do pâncreas. No jejuno ocorre o processo de digestão enzimática e absorção de nutrientes. No íleo ocorre pouca absorção dos nutrientes, sendo um caminho da digesta para o intestino grosso (Mello \& Silva, 2012).

O intestino grosso é dividido em três partes: ceco, cólon e reto; no intestino grosso ocorre a digestão microbiana, a absorção de nutrientes, a reabsorção de água, a produção e excreção de cecotrofos e das fezes. O ceco possui em sua extremidade anterior a ampola coli, uma estrutura constituída por quimiorreceptores, que monitoram o ceco no seu processo de fermentação, induzindo a saída do seu conteúdo pelo processo de cecotrofagia. Segundo Jaruche (2012), nos coelhos o ceco e muito desenvolvido, pois tem a função de auxiliar na fermentação das fibras, com a ajuda de uma microbiota específica, 
melhorando o teor de energia para os animais. No cólon proximal, acontece o ciclo cólico da água, fazendo com que ocorra o processo de moldura dos cecotrofos e os revestindo com muco. No cólon distal acontece a absorção da água e ocorre a formação das fezes, possuindo um esfíncter fusus coli na sua extremidade posterior, que possui quimiorreceptores que identificam através da acidez, a natureza da excreta, e se são cecotrofos ou fezes, induzindo a absorção dos cecotrofos. A porção final do trato gastrointestinal, é o reto, que excreta os cecotrofos para o processo de cecotrofagia, e as fezes para o ânus (Mello \& Silva, 2012).

Segundo Ferreira et al. (2006), a fisiologia dos coelhos ajuda a facilitar a utilização de dietas com alta concentração de forragens e baixa energia, fazendo com que os demais constituintes das forragens sejam utilizados com eficiência pelo organismo do animal.

\subsection{Desafios na produção de coelhos}

$\mathrm{O}$ mercado de produção de coelhos vive em busca de consumidores, que procuram carnes de alta qualidade, o que motiva os produtores a continuarem a investir nesse sistema. Pois, infelizmente o mercado muito das vezes não colabora para o aumento da produção (Machado, et al., 2014).

Segundo Machado e Scapinello (2011), o Brasil possui grande capacidade de produção de matérias primas para alimentação animal, o que provoca condições favoráveis para o desempenho da cunicultura. Porém, o mercado da cunicultura sofre com a ausência de políticas de apoio, assistência técnica qualificada e não possui um marketing bem desenvolvido no mercado de produção, devido a questões culturais e religiosas. A atividade basicamente é vista como uma alternativa de renda, onde poderia ser a principal atividade financeira, devido que no Brasil são poucos os estabelecimentos que trabalham exclusivamente com coelhos (Bonamigo, et al., 2015). Conquanto, observa-se a união de organizações e associações com grande esforço dos produtores de coelhos, o que pode melhorar o rumo da cadeia produtiva (Machado, et al., 2014).

Além do mercado para pelo e carne, existe um aumento significativo no mercado pet de coelhos, devido à grande variedade de raças de pequeno porte para a criação (Neto, et al., 2013). Segundo Machado (2012) e Machado, et al. (2014), mesmo com movimentação do mercado, os problemas de logísticas na cadeia produtiva, leva os produtores para vários problemas e desafios, já que a produção de coelhos não possui entidade nacional que coordene compras, vendas e marketing; o que leva a produção de coelhos no Brasil não ser comercial.

No Brasil, a produção de coelhos não é considerada uma atividade tradicional, focando em seus sistemas de produção, como criação de gado, aves e suínos. O que reforça a importância da criação de políticas públicas de forma para divulgar o consumo e a produção da espécie. Inicialmente o que deve ser melhorando é união dos produtores a partir de associações, pois cada produtor negocia individualmente o preço final, o que torna variável a rentabilidade de cada produção (Bonamigo, et al., 2015). Confirmando que o sistema de produção na cunicultura, necessita de uma maior profissionalização da atividade, possibilitando assim assumir uma atividade cada vez mais competitiva.

\subsection{Aditivos na alimentação de coelhos}

Os aditivos na alimentação animal podem contribuir para a obtenção da alta produtividade, redução dos custos e manutenção da qualidade dos sistemas de produção (Sakamura, et al., 2014). A Instrução Normativa 13/04 (alterada pela Instrução Normativa ${ }^{\circ}$ 44/15), aprovando o uso de aditivos para alimentação animal, a fim de garantir um nível adequado de proteção à saúde humana, aos animais e ao meio ambiente define os aditivos destinados à alimentação animal como "substância, microrganismo ou produto formulado, adicionado intencionalmente aos produtos, que não é utilizado normalmente como ingrediente, tenha ou não valor nutritivo e que melhore as características dos produtos destinados à alimentação animal, melhore o desempenho dos animais sadios ou atenda às necessidades nutricionais” (MAPA, 2017). 
Segundo Bertechini (2006), os aditivos são classificados de acordo com a sua natureza e função nas rações, podendo ser divididos em promotores de absorção, substâncias profiláticas, substâncias auxiliares e enzimas exógenas.

Os aditivos possuem várias classificações, cada uma destinada para um objetivo específico dentro dos sistemas de produção, desde promotores de crescimento até mesmo pigmentantes, visando valorizar o produto final comercializado. Dentre os aditivos na nutrição animal os aditivos zootécnicos, em especial, os antimicrobianos ou promotores de crescimento e anticoccidianos são os que apresentam maiores riscos à saúde humana. Esses aditivos vêm sendo largamente utilizados na produção animal há mais de 50 anos.

O MAPA (Ministério da Agricultura e Abastecimento) subdivide os aditivos zootécnicos em três categorias: digestivo, equilibradores de microbiota e melhoradores de desempenho. Esses aditivos visam primariamente a melhora dos parâmetros zootécnicos obtidos no sistema produtivo da espécie.

Segundo MAPA (2017), os aditivos digestivos são substâncias que facilitam a digestão dos alimentos ingeridos atuando sobre determinadas matérias-primas destinadas à fabricação de produtos para a alimentação animal, podendo ser classificados em:

Equilibradores de microbiota, que são microrganismos que formam colônias ou outras substâncias definidas quimicamente que têm um efeito positivo sobre a microbiota do trato digestório. Sendo os prebióticos, probióticos e suas associações os principais utilizados na nutrição de coelhos. E os melhoradores de desempenho, que são substâncias definidas quimicamente que visam melhorar os parâmetros de produtividade. Para Soares (1996), um promotor de crescimento ideal deve proporcionar um aumento do desempenho, apresentar um bom custo/benefício, ser atóxico, não alterar drasticamente a microbiota intestinal, atuar exclusivamente ao nível intestinal, não estar envolvido em transferência de resistência, não possuir resistência cruzada com outros antibióticos, principalmente em relação aos de uso humano, não deixar resíduos na carcaça dos animais após sua retirada e ser biodegradável.

Devido à preocupação em relação da qualidade dos produtos de origem animal comercializados pelas indústrias, o olhar do consumidor se atenta em relação à segurança alimentar, fazendo com que ocorra mudanças nos sistemas de produção mundialmente. Segundo Bertechini (2006), parte superior do formulário torna-se apenas uma questão de tempo para que questões relacionadas à proibição da utilização de antibióticos como promotores de crescimento aconteçam, intensificando a necessidade de aditivos alternativos que sejam próximos ou superiores nos benefícios sobre a resposta do desenvolvimento dos animais.

Diante das exigências do mercado consumidor de carnes e seus derivados, a procura por produtos alternativos que possam substituir os antibióticos é, sem dúvida, uma das linhas de pesquisa mais estudadas atualmente. Eyng (2012) ressalta que é necessário o aprimoramento das pesquisas com animais de produção e a publicação dos resultados para que os novos produtos sejam aceitos comercialmente. Devido a esta preocupação, tornou-se necessário estudo e desenvolvimento de aditivos naturais.

Entre eles estão os probióticos que são suplementos alimentares composto de microrganismos vivos que uma vez introduzidos no organismo dos animais, influenciam beneficamente a sua saúde pelo balanço microbiano intestinal. Agem melhorando os índices econômicos, conferindo maior produtividade, pelo aumento do ganho de peso e melhorias na eficiência alimentar. Segundo Bertechini (2006), o uso de probióticos na alimentação de coelhos, tem como função criar uma barreira intestinal contra agentes patógenos, beneficiando o desempenho desses animais.

Os prebióticos são substâncias presentes e/ou adicionados nos ingredientes das rações, podendo ser extraídos a partir de fontes naturais como plantas, leveduras e leite ou ser produzidos por hidrólise ácida ou enzimática parcial de polissacáridos, ou por reações de transglicosilação (Oku, 1996). Eles melhoram o equilíbrio da microbiota intestinal, favorecendo o animal nos processos de digestão e absorção dos nutrientes. Em coelhos o uso de prebióticos tem sido avaliado sobre os parâmetros 
zootécnicos como: consumo, ganho de peso e eficiência alimentar. Porém, o uso desse aditivo na alimentação de coelhos sobre o desempenho não está bem esclarecido (Bertechini, 2006).

Os simbióticos são compostos basicamente de associação de um probiótico e um prebiótico,que quando em contato com a solução, os microrganismos iniciam a sua multiplicação e favorecem o melhor estabelecimento, isto resulta em vantagens para o hospedeiro, tanto pela presença da microbiota benéfica quanto pela fermentação (Bertechini, 2006).

Os ácidos orgânicos são constituintes naturais de plantas e podem ser formados a partir da fermentação microbiológica no intestino e outros em rotas metabólicas. A utilização de ácidos orgânicos surge como uma alternativa ao uso de antibióticos como promotores de crescimento, tendo efeitos similares (Lehninger, et al., 1993).

\subsection{Nucleotídeos}

Os nucleotídeos são ésteres de fosfato de nucleosídos que contêm um açúcar ligado através de uma ligação glicosídica com bases de purina e pirimidina. As bases purinas são compostas por cinco anéis sendo classificadas como adenina, guanina e hipoxantina e as bases pirimidinas possuem seis anéis sendo conhecidas como citosina, timina e uridina. $\mathrm{O}$ grupo das purinas são pertencem a adenina e a guanina, presentes tanto no DNA como no RNA, e o grupo das pirimidinas pertencem a citosina, presente no DNA e RNA, a timina apenas presente no DNA e a uracila apenas presente no RNA (Nelson \& Cox, 2005; Rudolph, 1994)

Os nucleotídeos são moléculas de estrutura diversificadas compostos por uma base nitrogenada, um açúcar pentose e um ou mais grupos fosfatos. O açúcar pentose pode ser ribose (ácido ribonucleico) ou 2- desoxirribose (ácido desoxirribonucleico) e as bases nitrogenadas podem ser purinas ou pirimidinas. A união de vários nucleotídeos leva a formação de ácidos nucleicos e estes conjugados com as proteínas são classificados como nucleoproteína (Rodolph, 1994).

Em relação as condições fisiológicas, segundo Sanderson e He (1994), os nucleotídeos tem uma baixa capacidade de passar pela membra celular. No duodeno a capacidade de absorção dos nucleotídeos é maior, sendo estes os veículos para a entrada das purinas e pirimidinas nas células do tecido epitelial (Uauy, 1989).

Os nucleotídeos participam de vários processos bioquímicos essenciais para o funcionamento do organismo (Lehninger et al., 1995). Atuam como precursores dos ácidos nucléicos (DNA e RNA), fonte de energia (ATP e GTP), coenzimas (FAD, NAD e CoA) e reguladores fisiológicos (AMPc, GMPc) (Lerner \& Shamir, 2000). Nutricionalmente, os nucleotídeos não são considerados essenciais, pois são sintetizados via de novo pelo organismo utilizando aminoácidos como precursores ou por via de salvamento a partir da degradação de aminoácidos e nucleotídeos da dieta (Lerner \& Shamir, 2000). Porém, os nucleotídeos são considerados semi ou mesmo essenciais quando o organismo necessita de quantidade maior do que são sintetizados ou obtidos via salvamento, como no caso de rápido crescimento, estado de doença, consumo limitado de nutrientes ou distúrbio endógeno (Lerner \& Shmair, 2000).

Os nucleotídeos dietéticos são importantes para tornar disponíveis bases e nucleosídeos que podem ser utilizados imediatamente na síntese de nucleotídeos, via salvamento. Essa via é extremamente importante para os tecidos e órgãos cuja síntese de nucleotídeos é deficiente, mas que apresentam uma rápida divisão mitótica, como cérebro, eritrócitos, medula óssea, mucosa intestinal e linfócitos. Pois, nestes tecidos há uma grande demanda de ácidos nucléicos para atender a rápida divisão mitótica (Westwood, 1999). As células de rápido crescimento, como enterócitos, apresentam capacidade limitada para síntese de purinas e pirimidinas pela síntese de novo, portanto é necessária a suplementação exógena para manter a concentração de nucleotídeos (Uauy, 1990).

Os nucleotídeos precisam ser previamente hidrolisados para serem absorvidos nos enterócitos na forma de nucleosídeos, bases nitrogenadas e pequenas quantidades de nucleotídeos. As enzimas envolvidas neste processo são as fosfodiesterase e nucleosídeo fosforilase que são originadas no epitélio intestinal (Pereira, et al., 2011). 
Mais de $90 \%$ dos nucleotídeos dietético ou endógeno e de bases nitrogenadas são absorvidos nos enterócitos. O transporte de nucleosídeos dentro de enterócitos ocorre por difusão facilitada, transporte ativo e por mecanismo transportador dependente de sódio (Bronk \& Hastewell, 1987).

Do enterócito, parte dos produtos metabólicos da dieta, nucleosídeos e nucleotídeos endógenos entram na veia portal hepática. Essas moléculas são carreadas para os hepatócitos para posterior metabolismo. Do fígado, os mesmos são liberados dentro do sistema circulatório e entram no tecido muscular. Tais produtos não são reutilizados para a produção de nucleotídeos e não são absorvidos, sendo que as bases púricas e pirimídicas são catabolizadas a ácido úrico, $\beta$-alanina ou $\beta$-aminoisobutirato (Rudolph, 1994).

Estudos indicam que 2,0 a 5,0\% do nucleotídeo dietético são retidos no intestino delgado, fígado, tecido muscular esquelético, sendo que este valor pode ser maior em animais jovens e durante o jejum (Pereira et al.,2011). Os nucleotídeos dietéticos aumentam a absorção intestinal de ferro, afetam lipoproteínas e o metabolismo de ácidos graxos de cadeia longa poliinsaturada, têm efeito tópico na mucosa intestinal e fígado, e reduzem a incidência de diarréia (Schlimme, et al., 2000). Segundo Mateo e Stein (2004), os suínos em período de rápido crescimento necessitam de maior quantidade de nucleotídeos para expressar seu potencial genético.

Spring (2001) avaliou os efeitos da inclusão de uma fonte rica em nucleotídeos (Nupro®) sobre o desempenho e saúde de suínos desmamados. Os leitões alimentados com a dieta contendo Nupro® apresentaram uma tendência de maior ganho de peso, maior consumo de ração e melhor eficiência alimentar, além de apresentar menor incidência de diarreia.

Por desempenhar papel importante na função intestinal e no sistema imunológico, os nucleotídeos apresentam ser uma excelente fonte de inclusão na dieta dos animais. Em relação ao sistema imune, o aumento de ácidos nucleicos na dieta pode ativar os linfócitos. É necessária a suplementação de nucleotídeos na dieta para a manutenção normal do sistema imunológico, pois em linfócitos normais, há um turnover massivo de ácidos nucleicos para atender a rápida divisão mitótica que ocorre em resposta à estimulação pelo antígeno (Westwood, 1999).

Andrade, et al. (2011) observaram efeitos benéficos do uso de nucleotídeos na morfometria de órgãos e na histologia do epitélio intestinal dos leitões desmamados o que contribui para mantendo adequadas a produção de enzimas e a digestão e absorção dos nutrientes

Embora alguns benefícios do uso de nucleotídeos já sejam comprovados pela literatura, há poucos dados relativos aos benefícios do uso de nucleotídeos em animais de produção, e as informações sobre o seu papel no desenvolvimento do sistema imune e saúde intestinal são escassas, principalmente em coelhos. Tornando-se, portanto, evidente, a necessidade de estudos que comprovem a ação benéfica dos nucleotídeos sobre a imunidade e saúde intestinal e, seu consequente reflexo sobre o desempenho animal.

\subsection{Uso de nucleotídeos na dieta animal}

O uso de antibióticos com a finalidade de promotores de desempenho animal, está a tempos sendo retirados do mercado. Isto devido aos fatores de risco para a saúde pública devido os resíduos químicos que podem permanecer nos produtos comercializados por um longo tempo (Rossi, et al., 2007; Abreu, et al., 2010; Pelícia, et al., 2011).

A busca por produtos naturais através das pesquisas, visam sempre buscar o desempenho animal com qualidade e como consequência alimentos mais saudáveis para a alimentação humana. Devido a isto, muito estudos demonstram que os nucleotídeos incluídos em dietas, melhoram a resposta imunológica dos animais e como consequência o desempenho animal (Pelícia, et al., 2011).

Segundo Lenner e Shamir (2005), os nucleotídeos não são considerados essenciais para a alimentação animal, devido serem produzidos através do organismo utilizando aminoácidos como precursores. Porém, podem ser considerados semi 
essenciais, quando o organismo precisa de uma quantidade maior de nucleotídeos do que é sintetizada, em casos como doenças, fase de crescimento ou até mesmo consumo limitado.

Os nucleotídeos possuem uma dificuldade de atravessar a membrana celular, porém no duodeno possui uma alta capacidade de absorção. Sendo os nucleotídeos os maiores veículos para a entrada de purinas e pirimidinas nas células do tecido epitelial, sendo absorvidos no enterócito (Bronk \& Hastewell, 1897; Salati et al., 1984; Uauy, 1989; Sanderson e He, 1994).

Os animais conseguem sintetizar nucleotídeos através do citossol do hepatócito, onde as enzimas para a síntese das purinas e pirimidinas estão disponíveis. Porém, para que ocorra este processo, o organismo tem um alto custo metabólico, onde requer de uma grande quantidade de energia da forma de ATP (Rossi, 2007). Os nucleotídeos estão presentes em alimentos proteicos, sendo que os ingredientes contendo elementos celulares possuem um alto potencial de fontes dietéticas de nucleotídeos (Carver \& WAalker-, 1995).

Segundo Maribo (2003), em estudo realizado com suínos infectados com Escherichia colli, suplementados com extrato de levedura como fonte de nucleotídeo, observou uma redução da diarreia e melhor ganho de peso e a conversão alimentar dos animais, comparados com os demais tratamentos.

Abreu, et al. (2010), avaliaram a inclusão de glutamina, nucleotídeo e plasma suíno na dieta de leitões desmamados, puderam concluir que as utilizações dos três aditivos nas rações melhoraram o ganho de peso dos leitões de 21 a 42 dias de idade. No entanto, as combinações de glutamina + plasma suíno e nucleotídeo + plasma suíno, foram significativos devido a inclusão do plasma. Pois ele aumenta a palatabilidade e como consequência melhora o desempenho de leitões após o desmame.

Em estudo realizado por Zavarize et al. (2011), observaram que os tratamentos com 0,0; 0,5 e 1,0 \% de glutamina e 0,0 e 0,04\% de nucleotídeo na dieta de aves de 1 a 47 dias, não demonstraram efeito sobre as variáveis peso inicial e conversão alimentar. Porém, a adição de glutamina a 1,0\% demonstrou resultados positivos para o peso final, ganho de peso médio e consumo de ração.

Andrade, et al. (2011), avaliaram a inclusão de nucleotídeo através de um produto comercial, obtido pela hidrólise da levedura Saccharomyces cerevisiae, com 3,0 a 3,5\% de nucleotídeos e nucleotídeos, sobre as variáveis de desempenho, morfometria dos órgãos e histologia do epitélio intestinal de leitões recém-desmamados. Concluíram que a adição de nucleotídeos até ao nível de 600 ppm nas dietas, não melhoraram o desempenho de leitões recém-desmamados. Porém, os nucleotídeos demonstraram efeitos benéficos na morfometria de órgãos e na histologia do epitélio intestinal dos leitões, podendo ser indicado até o nível de $150 \mathrm{ppm}$.

Pelícia, et al. (2011), analisaram a inclusão de nucleotídeos na dieta de aves no período de 1 a 42 dias, sobre a taxa de turnover do carbono da mucosa intestinal de frangos de corte submetidos ou não ao desafio por coccidiose. Concluindo que a suplementação com nucleotídeos na ração de frangos de corte acelerou o turnover da mucosa intestinal durante o crescimento e maturação do intestino e durante regeneração desse tecido após os danos causados em sua estrutura, demonstrando que os nucleotídeos são importantes para a manutenção e função da mucosa intestinal.

Faveri, et al. (2015), também avaliaram a morfologia intestinal e o desempenho de frangos de corte na fase de crescimento, com e sem adição de nucleotídeos na dieta, com diferentes níveis proteicos. Observaram que com a adição de nucleotídeos nas dietas de baixa proteína com 1,062\% de lisina digestível, é possível manter a integridade intestinal e o desempenho de frangos de corte.

Com bases nestes estudos, pode se observar os pontos positivos da adição de nucleotídeos no desempenho dos animais e também nas características histológicas, que ajudam a melhorar a absorção de nutrientes e como consequência, melhoram o desempenho animal. 


\section{Considerações Finais}

O mercado de produção de coelhos tanto para a produção de carne, quando para a produção pet, possui grande capacidade de se tornar uma atividade reconhecida em grande proporção no Brasil. Sendo que, nos sistemas de produção a alimentação é um dos mais importantes estágios para o desenvolvimento de mercado. Devido a isto, se destaca a importância de mais estudos, pesquisas e divulgações de trabalhos na área da cunicultura, que possam ajudar a manter/melhorar a qualidade de produção, visando sempre estar de acordo com as leis, e objetivando aumentar o conhecimento sobre a produção de coelhos e como consequência, apresentar os benefícios de seus produtos para a saúde humana.

\section{Agradecimentos}

Ao Instituto Federal de Educação, Ciência e Tecnologia do Sul de Minas Gerais - Campus Muzambinho;

A Universidade José do Rosário Vellano - UNIFENAS/Alfenas-MG;

A Coordenação de Aperfeiçoamento de Pessoal de Nível Superior - CAPES

\section{Referências}

Abreu, M. L. T., Donzele, J. L., Saraiva, A., Oliveira, R. F. M., Fortes, E. I., \& Granã, G. L. (2010) Glutamina, nucleotídeos e plasma suíno em rações para leitões desmamados. Revista Brasileira de Zootecnia, 3(39), 05-12.

ACBC (2010). Consumo de carne de coelho. <http://acbc.org.br/site/index.php/boletim-de-cunicultura2/edicoes-publicadas>

Andrade, C., Vezzoni, V. A., Costa, L. B., Berenchtein, B., Barreto, G. M., \& Miyada, V. S. (2011) Levedura hidrolisada como fonte de nucleotídeos para leitões recém-desmamados. R. Bras. Zootec., 40(4),788-796.

Bertechini, A.G. (2006) Nutrição de monogástricos. Lavras/mg: Editora Ufla, 301.

Bonamigo, A., Winck, C. A., Sehnem, S. (2015) Diagnóstico da produção e comércio cunícula no Estado de Santa Catarina. Revista Brasileira de Cunicultura, $7(1), 9-33$.

Bronk, J. R., \& Hastewell, J. G. (1987). The transport of pyrimidines into tissue rings cut from rat small intestine. Journal of Physiology, Paris, 382(1), 475488 .

Carver, J. D., \& Walker, W. A. (1955). The role of nucleotides in human nutrition. Nutrition. Biochemistry, Stoneham, 6(2), 58-72.

Duarte, C. L. G. (2011) A cadeia produtiva do coelho. Cunicultura em Foco, 1, 9-10.

Eyng, C. (2012). Própolis bruta e estrato etanólico de própolis na alimentação de frangos de corte. 2012.147 f. Tese (Doutorado) - Curso de Pós-graduação em Produção Animal, Universidade Estadual de Maringá Centro de Ciências Agrárias, Maringá.

Faveri, J.,Murakami, A.,Potença, A.,Eyang, C., Marques, A. F. Q., \& Santos, T. C. (2015). Desempenho e morfologia intestinal de frangos de corte na fase de crescimento, com e sem adição de nucleotídeos na dieta, em diferentes níveis proteicos. Pesq. Vet. Bras. 35(3):291-296.

Ferreira, W. M., Saad, F. M. O. B., \& Pereira, R. A. N. (2006). Fundamentos Da Nutrição De Coelhos. Lavras: Universidade Federal de Minas Gerais Escola de Veterinária Departamento de Zootecnia, p. 92.

Ferreira, F. N. A., Ferreira, W. M., Mota, K. C. N., Neta, C. S. S., Lara, L. B., \& Santos, E. A. (2015). Avaliação nutricional do bagaço de cana-de-açúcar enriquecido com vinhaça em dietas para coelhos em Crescimento. Revista Caatinga, 28(4), 217 - 226.

FOA STAT, Dados. 2017. <http://www.fao.org/faostat/en/\#data/QA>

FAO (2017). Statistical database. <http://www.fao.org/faostat/en/\#country>

Forrester-Anderson, I. T., Mcnitt, J., Way, R., \& Way, M. (2006). Fatty acid content of pasture-reared fryer rabbit meat. Journal Of Food Composition And Analysis, 19(6-7), 715-719.

Gil, A. C. (2002). Como elaborar projetos de pesquisa (Vol. 4, p. 175). Atlas.

IBGE, Censo 2012. <http://www.ibge.gov.br/home/estatistica/indicadores/agropecuaria/ producaoagropecuaria.

IBGE. (2017). Resultados do censo Agropecuário. https://censoagro2017.ibge.gov.br/templates/censo_agro/resultadosagro/pecuaria.html.

Jaruche, Y. G. (2012). Ceco, cecofagia, cecotrofagia, cecotrofia, cecotróficos, cecotrofos, coprofagia, coprofágicos e coprófagos. Paraná: Uem,

Klinger, A. C. K. \& Toledo, G. S. P. (2018). CUNICULTURA: didática e prática na criação de coelhos. Santa Maria, Rs: Ufms, 128. 
Lehninger, A. L., Nelson, D. A., \& Cox, M. M. (1993). Principlesof Biochemistry. Worth Publishers.

Lehninger, A. L., Nelson, D. L., \& Cox, M. M. (1955). Nucleotídeos e ácidos nucleicos. In: Lehninger, A.L.; Nelson, D.L.; Cox, M.M. (Eds.) Princípios de bioquímica. São Paulo: Sarvier, cap. 12. p. 242-268.

Lerner, A. \& Shamir, R. (2000). Nucleotides in infant nutrition: a must or an option. IMAJ, Haifa, 2(10), $772-774$.

Machado L. C., \& Ferreira, W. M.; Scapinello, C. Manual de formulação de ração e suplementos para coelhos. ACBC, 2011.

Machado, L. C. (2017). Nota técnica: Legislação de coelhos para laboratório. http://acbc.org.br/site/index.php/notas-tecnicas/legislacao-de-coelhos-paralaboratorio.

Machado, L. C., Scapinello, C., Ferreira, W. M., Brum, B. J., Ferreira, F. N. A., Araújo, I. G., \& Jaruche, Y. G. (2014). Sistemas de produção em cunicultura. Revista Brasileira de Cunicultura, Bammbuí-Mg, 6(1), 1-2.

Machado, L. C. (2012). Opinião: Panorama da cunicultura Brasileira. Revista Brasileira de Cunicultura, 1(2).

Machado, L. C. \& Ferreira, W. M. (2012). A cunicultura como alternativa ao combate à fome. <http://www.acbc.org.br/>

Machado, L. C., Castilha, L. D., \& Tvardovskas, L. (2021) Cunicultura em números. Boletim de cunicultura ACBC, ed. 5, 21.18 - 23.

MAPA. (2017). Aditivos. <http://www.agricultura.gov.br/assuntos/insumosagropecuarios/insumos-pecuarios/alimentacao-animal/aditivos>.

Maribo, H. (2033). Weaning pigs without antibiotic growth promoters: strategies to improve health and performance. In: Nutritional Biotechnology in the feed and food industries, 19., Lexington, Anais. Lexington: Nottingham University Press, 1, 179-184.

Mateo, C. D. \& Stein, H. H. (2004). Nucleotides and young animal health: can we enhance intestinal tract development and immune function. In: Biotechnology in the feed industry, 20., Lexington, Anais... Lexington: Nottingham University Press, 1. 159-170.

Mello, H. V. \& Silva, J. F. (2012). Criação de Coelhos. (2a ed.), Aprenda Fácil, p. 275.

Militão, L. (2011). Entrevista. Cunicultura em Foco, 1, 11-12.

Nelson, D. L. \& Cox, M. M. (2005). Nucleotides and Nucleic Acids. In: Nelson, D.L. e Cox, M. M. (Ed). Lehninger, Principles of Biochemistry. (4a ed,), Worth Publishers, p. 273-275.

Neto, P. B., Jaruche, Y. G., Araujo, I. G., Scapinello, C., \& Vasconcelos, R. S. (2013). Alimentação e nutrição de coelhos Pet. Revista Pet Food Brasil.

Pelícia, V. C., Zavarize, K. C., Ducatti, C., Stradiotti, A. C., Pezzato, A. C., Araujo, P. C., Mituo, M. A. O., Madeira, L. A., \& Sartori, J. R. (2011). Nucleotídeos na dieta de frangos de corte e seus efeitos sobre taxa de turnover da mucosa intestinal antes e após lesões causadas por coccidiose. Ciência Rural, 41(9), 1562-1569.

Romain, I. J. (2015). Cultivo de coelhos e agricultura familiar. <http://www.fao.org/family-farming/detail/es/c/335193/>

Roos, E., Bajzelj, B., Smith, P., Patel, M., \& Little, D. (2016). Garnett, T. Protein futures for Western Europe: potential land use and climate impacts in 2050. Regional Environmental Change, 17(2), 367-377.

Rossi, P., Xavier, E. G., \& Rutz, F. (2007). Nucleotídeos na nutrição animal. Revista Brasileira de Agrociência, 13(1),.05-12.

Rudolph, L.B. (1994). The biochemistry and physiology of nucleotides. Journal Nutrition 124, 124-127. https://academic.oup.com/jn/articleabstract/124/suppl_1/124S/4730328?redirectedFrom=fulltext.

Salati, L. M., Gross, C. J., \& Henderson, L. M. (1984). Absorption and metabolism of adenine, adenosine-5 monophosphate, adenosine and hypoxanthine by the isolated vasculary perfused rat small intestine. Journal of Nutrition, Philadelphia, 114(4), 753-760.

Sanderson, I. R. \& HE, Y. (1944). Nucleotide uptake and metabolismo by intestinal epithelial cells. Journal of Nutrition, Philadelphia, $124,131-137$.

Sakamura, N. K., Silva, J. H. V., \& Costa, F. G. P. (2014). Nutrição de não ruminantes. Funep, p. 678.

Santomá, G., De Blas, J. C., CAarabonp, R., \& Fraga, M. J. (1989). Nutrition of rabbits. Departamento de producción animal, Universidad Politécnica de Madrid, Spain, Cyanamid Ibéria S.A., Apto 471, 138.

Schlimme, E., Martin, D., \& Meisel, H. (2012). Nucleosides and nucleotides: natural bioactive substances in milk and colostrum. British Journal of Nutrition, 84, S59-S68,

Scapinello C., Araujo I. G., \& Jaruche Y. G., Ponciano Neto B. Sistemas de Criação de coelhos. In: Seminário Nacional De Ciencia E Tecnologia Em Cunicultura, 4. Botucatu. Anais... CD ROM.

SEBRAE. (2016). Fornecimento de elementos para criação de coelhos destinados ao abate. https://www.sebrae.com.br/sites/PortaSebrae/Busca?q=matriz $\% 20$ de $\% 20$ corte $\% 20$ gaiola $\% 20$ bebedouro $\% 20$ abatedouro $\% 20$ equipamento $\% 20 \mathrm{de} \%$ mento $\% 20$ atom $\%$ C3\%A1tico $\% 20 \mathrm{cuntura} \% 20$ abatedouro $\% 20 \mathrm{cria} \% \mathrm{C} 3 \% \mathrm{~A}$ 7\%C3\%A3o\%20Abate\%20coelho\%20colho\%20bebedouro $\% 20$ matriz\%20de $\% 20$ corte $\% 20$ cunicultura $\% 20$ gaiola $\% 20$ cria $\%$ C $3 \%$ A7\%C3\%A3o $\% 20$ fornecedor $\% 20$ fornecedor\%20equipamento\%20de\%20acionamento\%20a

Simonato, M. T. (2008). Rendimento e qualidade de carcaça de coelhos submetidos a diferentes períodos de jejum pré-abate. 2008.36 f. Dissertação (Mestrado) - Curso de Zootecnia, Universidade Federal Rural do Rio de Janeiro.

Spring, P. (2001). Effect of Nupro® 2000 on commercial pig performance in Switzerland. Zurich. 
Research, Society and Development, v. 10, n. 13, e85101320990, 2021

(CC BY 4.0) | ISSN 2525-3409 | DOI: http://dx.doi.org/10.33448/rsd-v10i13.20990

Uauy, R. (1989). Textbook of Gastroenterology and Nutrition in Infance. Raven Press, Ltda, p. 1383.

Uauy, R., \& Strigel, G., Thomas, R. (1990) Effect of dietary nucleosides of growth and maturation of the developing gut in rat. Journal of Pediatric Gastroenterology and Nutrition, Philadelphia, 10(4), 497-503.

Westwood, O. M. R. (1999). The scientific basics for health care. London: Yimes Mirror Internacional Publishers, 616p. Amazon.

Zavarize, K. C., Sartori, J. R., Pelícia, V. C., Pezatto, A. C., Araújo, P. C., Stradiotti, A. C., \& Madeira, L. A. (2011). Glutamina e nucleotídeos na dieta de frangos de corte criados em sistema alternativo. Arch. Zootec. 60 (232): 913-920. 